\title{
Caracterização geoecológica do estuário do rio Pacoti-Ceará: ações para um planejamento integrado
}

\author{
Geoecological characterization of the Pacoti River estuary: actions for an integrated \\ planning.
}

\author{
BARBOSA, L. N. ${ }^{1}$; LIMA, V. G. F ${ }^{2}$; FARIAS, J. F. ${ }^{3}$; SILVA, E. V. ${ }^{4}$ \\ larissanerisb@gmail.com
}

\begin{abstract}
Resumo
Os estuários são zonas de interação marinho-costeira, que dão origem a diferenciadas feições de relevo, fauna, flora, solos e outros aspectos característicos de sua dinâmica. Tal diversidade tem elevado o interesse humano por estes ambientes que sofrem continuamente com as pressões antrópicas sobre seus recursos. Destaca-se o estuário do rio Pacoti, localizado nos municípios de Fortaleza, Aquiraz e Eusébio, na Região Metropolitana de Fortaleza (RMF), litoral leste do Estado do Ceará. A partir do enfoque sistêmico, adotou-se como metodologia para o desenvolvimento da pesquisa a Geoecologia da Paisagem, que permite desde identificar problemáticas até propor medidas de conservação. Posteriormente, houve a realização de levantamentos ambientais da porção que corresponde ao estuário do rio Pacoti. Assim, foram caracterizados os sistemas ambientais por meio da realização de pesquisas bibliográficas, coleta de informações e técnicas de geoprocessamento, criando um banco de dados em um Sistema de Informações Geográficas (SIG). Avalia-se que os produtos gerados por esta pesquisa possuem relevância, pois incentivam ações de planejamento e gestão nas comunidades circunvizinhas, levando em consideração as potencialidades, fragilidades e limitações das áreas, a partir de práticas menos impactantes ao ambiente natural, gerando subsídios para a elaboração do plano de manejo da Área de Proteção Ambiental.
\end{abstract}

Palavras-chave: Estuários, Geoecologia da Paisagem e Planejamento Ambiental.

\begin{abstract}
Estuaries are zones of marine-coastal interaction, which give rise to different relief features, fauna, flora, soil and other characteristic aspects of its dynamics. Such diversity has elevated the human interest in these environments that continuously suffer from anthropogenic pressures on their resources. We highlight the estuary of the Pacoti river, located in the cities of Fortaleza, Aquiraz and Eusébio, in the Metropolitan Region of Fortaleza (RMF), east coast of Ceará. From the systemic approach, was adopted as a methodology for the development of research the Landscape Geoecology, which allows from identifying problem to propose conservation measures. Later, there was the realization of environmental surveys of the portion that corresponds to the estuary of Pacoti river. Thus, environmental systems were characterized by conducting literature searches, information gathering and geoprocessing techniques, creating a database in a Geographic Information System (GIS). It is estimated that the products generated by this research are relevant because encourage actions of planning and management in the surrounding communities, taking into account the potential, weaknesses and limitations of the areas, from less impactful practices to the natural environment, and generate subsidies for the preparation of the
\end{abstract} Environmental Protection Area management plan.

Keywords: Estuaries, Landscape Geoecology and Environmental Planning.

\section{INTRODUÇÃO}

A intensa dinâmica dos sistemas costeiros, oriunda da interação marinha e continental, forma um amplo conjunto de ecossistemas diferenciados: praias arenosas e dunas, manguezais, restingas, barreiras de recifes, lagunas, enseadas e baías, costões rochosos, deltas e os estuários, dentre outros (MANN, 2000) que via ciclos de deposição e erosão dão origem a feições particulares e características destas áreas, denominadas planícies costeiras.

\footnotetext{
${ }^{1}$ Larissa Neris Barbosa, Departamento de Geografia/Laboratório de Geoecologia da Paisagem e Planejamento Ambiental, Universidade Federal do Ceará, Fortaleza-CE, Brasil

${ }^{2}$ Victor Gabriel Ferreira Lima, Departamento de Geografia, Universidade Federal do Ceará, Fortaleza-CE, Brasil

${ }^{3}$ Juliana Felipe Farias, Departamento de Geografia, Universidade Federal do Rio Grande do Norte, Ntala- RN, Brasil

${ }^{4}$ Edson Vicente da Silva, Departamento de Geografia/Laboratório de Geoecologia da Paisagem e Planejamento Ambiental,

Universidade Federal do Ceará, Fortaleza-CE, Brasil
} 
Os estuários são representados pelas desembocaduras dos rios, mas não isoladamente, pois modificam consideravelmente suas zonas de influência, sendo representados também, geralmente, pelo baixo curso das bacias hidrográficas, nos quais "a declividade é praticamente nula e as correntes fluviais não tem mais capacidade de entalhe na superfície" (SOUZA, 2000). Apresentando características funcionais únicas dentre todos os ecossistemas aquáticos, pois neste contexto de transição fluvial e marinha, atuam como "berçário", abrigo e espaço de reprodução para centenas de espécies, além de fornecerem proteção ao continente das instabilidades oriundas de eventos climáticos marinhos.

Denotam-se como áreas com elevados índices de salinidade, solos argilosos e lamacentos (gleissolos), fauna e flora endêmicas, características que interferem diretamente no uso/ocupação e dinâmica socioeconômica destas áreas, pois representam empecilhos ao estabelecimento de moradias sem prévio aterramento, além de configurar-se como espaço de provimento de insumos, através da atividade extrativista. As formas de ocupação e o uso dos recursos naturais, de forma desordenada, pela atividade industrial têm exposto estes ambientes à desestabilização, conferindolhes repercussões, de cunho ambiental, negativas ao longo do tempo, assim como destaca PintoCoelho e Havens (2015, p.87):

\begin{abstract}
Apesar de serem sistemas altamente adaptados às flutuações climáticas e ambientais, com grande resiliência e resistência às intempéries naturais, os estuários e demais áreas costeiras demonstram também uma enorme fragilidade ambiental, já que são facilmente perturbados e, muitas vezes, de modo irreversível pelas atividades humanas.
\end{abstract}

No caso em questão, tratamos do rio Pacoti, que nasce na Serra de Baturité e se prolonga por cerca de $150 \mathrm{~km}$ até desaguar no Oceano Atlântico, seu estuário está localizado nas coordenadas $38^{\circ}$ 24' 27 'W e $3^{\circ}$ 51' 07'S (Figura 1), no litoral leste do estado, em uma das onze regiões hidrográficas do Estado do Ceará divididas por unidade de planejamento, a Bacia Metropolitana do Baixo Pacoti, que abrange três municípios: Fortaleza, Aquiraz e Eusébio. 


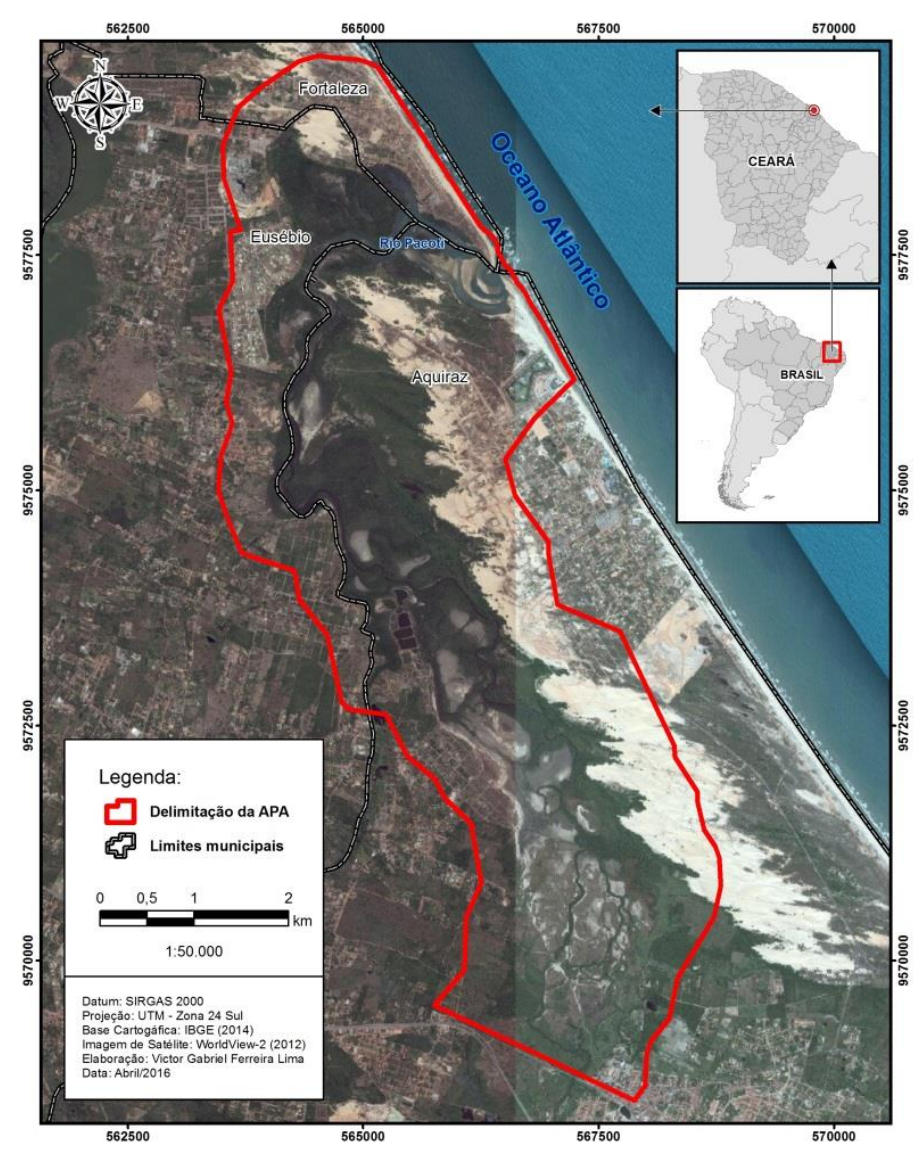

Figura 1: Mapa de localização da APA do rio Pacoti. Elaboração: LIMA, V. G. F. (2016).

Este sistema estuarino abrange faixas contínuas de planície litorânea, tabuleiro litorâneo e de mar litorâneo, com feições características da dinâmica eólica em ambientes costeiros representadas pelos campos de dunas, que geram, pela boa capacidade de armazenamento hídrico, lagoas interdunares, "além da presença de linhas de recife de arenito (beachrocks), aproximadamente paralelas à linha de costa, que alteram o padrão de arrebentação das ondas", assim como salienta o MMA (2006, p.157).

Neste contexto, criou-se a Área de Proteção Ambiental (APA) do rio Pacoti, por meio do decreto $\mathrm{N}^{\mathrm{o}}$ 25.778, de 15 de fevereiro de 2000 "que visa preservar e proteger esta área de relevância ambiental, de equilíbrio ecológico bastante frágil, portanto, de uma proteção especial por parte do poder público e da sociedade, além da importância de se preservar a bacia do rio Pacoti para o abastecimento de água de Fortaleza" (CEARÁ, 2000).

Neste estudo, utilizou-se a Geoecologia da Paisagem, proposta metodológica de Rodriguez; Silva e Cavalcanti (2013), que abrange as etapas de organização, inventário, análise, diagnóstico e proposição, facilitando a organização e a sistematização lógica das informações obtidas, possuindo ainda bases sistêmicas na análise integrada da paisagem, o que contribui para a compreensão da 
dinâmica dos sistemas naturais e antrópicos, favorecendo o pensamento sobre os fundamentos e as metodologias do planejamento ambiental.

Com isso, busca-se promover a discussão acerca da importância dos sistemas estuarinos, em razão de relevância ambiental, social e biológica, com fins a manutenção destes ambientes e garantia de uso das gerações futuras. Para isso, no recorte estudado, utilizou-se da abordagem geoecológica para identificação das problemáticas e posteriormente elaborou-se propostas de manejo sustentável, que buscam subsidiar ações efetivas de monitoramento e fiscalização, demonstrando o atual nível de conservação destes ambientes e estratégias para manutenção do ecossistema local.

\section{METODOLOGIA}

As ações realizadas durante o desenvolvimento da pesquisa foram divididas em duas fases. A primeira (organização, inventário e análise) dedicou-se a realizar trabalhos de revisão bibliográfica, análise de dados pré-existentes sobre o estuário e trabalhos de campo com coleta de dados. Nos trabalhos de campo, desenvolvidos ao longo dos 3 anos de pesquisa, foram realizadas investigações a respeito dos aspectos físicos que compõem a área de estudo e adjacências, identificando as principais unidades geoambientais, com ênfase nos recursos naturais e nas formas de uso e ocupação do solo, com os devidos registros fotográficos e marcação de coordenadas geográficas a partir do Sistema de Posicionamento Global (GPS).

Neste contexto, em uma segunda fase (diagnóstico e proposição) realizaram-se as atividades de análises espaciais e geoprocessamento, onde a partir das imagens do satélite WorldView-2, do ano de 2012, foram elaborados mapas com o auxílio de um Sistema de Informações Geográficas (SIG), mais especificamente do software livre QGIS 2.8, utilizado para tratamento, análise de dados espaciais, georreferenciamento das imagens, assim como para a composição final do mapa.

Utilizou-se arquivos "shape" fornecidos por instituições de pesquisa responsáveis, como o Instituto Brasileiro de Geografia e Estatística (IBGE), Companhia de Pesquisa de Recursos Minerais (CPRM), Instituto de Pesquisa e Estratégia Econômica do Ceará (IPECE), Departamento Nacional de Produção Mineral (DNPM) e Superintendência Estadual de Meio Ambiente do Ceará (SEMACE), com intuito de obter localizações geográficas precisas de algumas delimitações naturais e administrativas, que subsidiaram a elaboração do mapa de localização.

Assim, a proposta metodológica da Geoecologia da Paisagem, de Rodriguez; Silva e Cavalcanti (2013) foi aplicada em razão de fornecer parâmetros de análise da paisagem, com base no enfoque sistêmico, permitindo dividir o território em unidades geoambientais (ou geoecológicas) a partir da “individualização, tipologia e unidades regionais e locais da paisagem" (2013, p. 65) de acordo com 
a escala. Permitindo, para isso, o uso de SIGs na cartografia da paisagem, além de bases à proposição de medidas de planejamento e manejo ambiental.

Os fundamentos teóricos iniciais desta metodologia foram estruturados por Dokuchaev, que no final do século XIX utilizou da abordagem ecológica da paisagem para analisar o uso da natureza tomando como base o ser humano e a sociedade. Já Karl Troll viu a necessidade de se pensar em uma ciência que tenha um enfoque sobre os complexos naturais, considerando as paisagens naturais como derivadas da inter-relação entre os seres vivos e seu ambiente, o que viabilizou o surgimento em 1939 da Ecologia da Paisagem, posteriormente denominada de Geoecologia das Paisagens em 1966 (RODRIGUEZ; SILVA, 2013)

Conjugando duas abordagens, a Geoecologia da Paisagem, refere-se na primeira, à paisagem analisada a partir do princípio da diferenciação espacial da superfície terrestre e da inter-relação entre os fenômenos naturais, e a segunda partindo de uma abordagem biológico-ecológica, enfocando as interações entre os fenômenos naturais e os sistemas ecológicos (RODRIGUEZ; SILVA, 2013).

De acordo com Farias (2015, p.49):

É possível destacar alguns fatores que contribuíram de maneira significativa para o estabelecimento das bases da Geoecologia, como: o desenvolvimento da Escola Naturalista, alemã e russa, do século XIX a meados do século XX; a concepção geossistêmica, elaborada na União Soviética; os trabalhos desenvolvidos por Karl Troll e outros estudiosos alemães no século XX; e a Escola de Paisagem Cultural de Karl Sauer no século XX .

A partir de 1960, a Geoecologia das Paisagens se difunde como uma linha investigativa que busca compreender os complexos territoriais nas escalas de análise global, e local, tendo como um dos principais objetivos da análise geoecológica, fornecer subsídios para resolver os problemas decorrentes do impacto de fatores antropogênicos ou processos individuais espontâneos em limites territoriais do espaço terrestre (RODRIGUEZ; SILVA, 2013).

\subsection{CARACTERIZAÇÃo DA ÁREA}

O estuário do rio Pacoti, tem uma área de $362 \mathrm{~km}^{2}$ e foi delimitado por critérios de salinidade e também pela Área de Proteção Ambiental de nome homônimo, que visa resguardar o ambiente influenciado pela ação das marés e as feições geradas a partir dele, representado pela planície flúvio-marinha e seu ecossistema manguezal com cerca de 160 hectares de extensão (GORAYEB; SILVA e MEIRELES 2004, p.1; 2005, p.145).

Assim, considerando-se a elevada complexidade dos sistemas ambientais da área e suas respectivas características de geomorfologia, geologia, solos e vegetação, de forma inter- 
relacionada, elaborou-se o quadro 1, que sistematiza estes aspectos ambientais, que estão submetidos ao clima sub-úmido, por se localizar no litoral cearense, com irregularidades anuais e interanuais das chuvas.

\begin{tabular}{|c|c|c|c|}
\hline \multicolumn{4}{|c|}{ Quadro 1: Caracterização Física e Ambiental do estuário do rio Pacoti, Ceará } \\
\hline Geomorfologia & Geologia & Solos & Vegetação \\
\hline $\begin{array}{l}\text { Planície Litorânea: feições } \\
\text { de praia, campos de dunas } \\
\text { móveis, campo de dunas } \\
\text { fixas, paleodunas e planície } \\
\text { flúvio-marinha. }\end{array}$ & $\begin{array}{c}\text { Q2e*: Areias } \\
\text { esbranquiçadas quartzosas, } \\
\text { bem classificadas, } \\
\text { ocorrendo leitos mais } \\
\text { escuros com concentrações } \\
\text { de minerais pesados. }\end{array}$ & $\begin{array}{c}\text { Neossolos Quartzarênicos } \\
\text { Distrófico, Gleissolos } \\
\text { Sálico e Gleissolos } \\
\text { Tiomórfico. }\end{array}$ & $\begin{array}{c}\text { NC*: Herbeto } \\
\text { Campesinato, Edáfico } \\
\text { marino arenoso e Arboreto } \\
\text { Edáfico Marino-Limoso } \\
\text { NP***: Vegetação } \\
\text { pioneira, vegetação } \\
\text { psamófila, vegetação de } \\
\text { mangue, vegetação costeira } \\
\text { arbustiva de dunas }\end{array}$ \\
\hline $\begin{array}{l}\text { Planície Flúvio-Lacustre e } \\
\text { áreas de inundação sazonal }\end{array}$ & $\begin{array}{c}\mathrm{ENb}^{*} \text { : Arenitos argilosos } \\
\text { de tonalidade variegada } \\
\text { com leitos conglomeráticos } \\
\text { e nódulos lateríticos na } \\
\text { base. }\end{array}$ & $\begin{array}{l}\text { Neossolos e Gleissolos } \\
\text { Sálicos }\end{array}$ & $\begin{array}{c}\text { NC: Arboreto Edáfico } \\
\text { Fluvial } \\
\text { NP: Vegetação ciliar e de } \\
\text { várzea }\end{array}$ \\
\hline $\begin{array}{l}\text { Planície Fluvial do Rio } \\
\text { Pacoti }\end{array}$ & $\begin{array}{c}\text { Q2a*: Argilas, areias } \\
\text { argilosas, quartzosas e } \\
\text { quartzo feldspáticas, } \\
\text { conglomeráticas ou não, } \\
\text { cascalhos argilas orgânicas. }\end{array}$ & $\begin{array}{l}\text { Neossolos e Gleissolos } \\
\text { Sálicos }\end{array}$ & $\begin{array}{c}\text { NC: Arboreto Edáfico } \\
\text { Fluvial } \\
\text { NP: Vegetação ciliar e de } \\
\text { várzea }\end{array}$ \\
\hline $\begin{array}{l}\text { Glacis de Deposição Pré- } \\
\text { Litorâneos: tabuleiros } \\
\text { costeiros dissecados em } \\
\text { interflúvios tabulares }\end{array}$ & $\begin{array}{l}\text { EגM*:Suíte Magmática } \\
\text { Messejana: tefritos, } \\
\text { fonolitos, traquitos, tufos } \\
\text { alcalinos e essexitos } \\
\text { porfiríticos, ocorrendo } \\
\text { associados ou } \\
\text { isoladamente. }\end{array}$ & $\begin{array}{c}\text { Neossolos Quartzarênicos } \\
\text { Distrófico e Argissolos } \\
\text { Vermelho Amarelo } \\
\text { Distrófico }\end{array}$ & $\begin{array}{c}\text { NC: Fruticeto Estacional } \\
\text { Semicaducifólio Esclero- } \\
\text { mesomórfico } \\
\text { NP: Vegetação } \\
\text { subcaducifólia e de } \\
\text { tabuleiro }\end{array}$ \\
\hline
\end{tabular}

* Sigla referente à unidade litológica descrita, com base no Mapa Geológico do Ceará, executado pela Companhia de Pesquisas em Recursos Minerais - CPRM (2003).** NC: Nome científico e *** NP: nome popular. Adaptado de CPRM (2003); Nascimento (2003), MMA (2001) e Fernandes (1998).

Quadro 01. Caracterização Física e Ambiental do Estuário do rio Pacoti. Fonte: Org. por Barbosa (2016).

As unidades geomorfológicas de maior expressão na área são os tabuleiros costeiros e as planícies litorâneas, caracterizadas como:

Os tabuleiros, constituem relevos predominantemente planos com trechos suavemente ondulados, distribuídos ao longo da região do litoral em faixa praticamente contínua, entre as planícies costeiras e as depressões sertanejas, apresentando larguras variáveis de até $60 \mathrm{~km}$. São constituídos por sedimentos areno-argilosos de tonalidade variada com leitos conglomeráticos e nódulos lateríticos na base do Grupo Barreiras, datada do Tércio-Quaternário e sobrepostos diretamente sob o embasamento cristalino e em pequenos trechos sob rochas datadas do cretáceo (SOUZA, 2000). Ainda podendo ser destacado o afloramento, referente à Suíte Intrusiva Messejana (Magmatismo Messejana) datada dos últimos eventos tectônicos devido à abertura do Oceano Atlântico. 
As planícies costeiras ou baixadas litorâneas são superfícies deposicionais de baixo gradiente, formadas por sedimentação predominantemente subaquosa. Elas margeiam corpos de água de grandes dimensões, como o mar ou oceano, e são comumente representadas por faixas de terrenos emersos, geologicamente muito recentes e compostos por sedimentos marinhos, continentais, flúvio-marinhos, lagunares, paludiais etc., em geral de idade quaternária (SOUZA, 2000). Neste sentido, Suguio (2010, p.219) afirma que as flutuações dos níveis relativos do mar e o transporte longitudinal de areia por correntes de deriva litorânea, associados com mudanças paleoclimáticas, controlaram a evolução das planícies costeiras do Brasil.

\section{RESULTADOS E DISCUSSÃO}

Segundo Pinto-Coelho e Havens (2000, p.87) uma das características que unem quase todos os sistemas costeiros do mundo é a elevada densidade populacional que ocorre nessas áreas, onde vivem cerca de 500 milhões de pessoas, característica que acaba por expor os ambientes litorâneos a diversos tipos de agressão, assim como Sales (1993, p.133) salienta que o loteamento da zona litorânea gera problemáticas ambientais como o aplainamento de dunas, poluição dos recursos hídricos, acúmulo de lixo e dentre outros.

A condição de degradação, encontrada na maioria dos ambientes litorâneos, apresenta-se também no estuário do rio Pacoti, que vem sendo acometido pelo despejo irregular de resíduos sólidos, emissão de efluentes domésticos e industriais, ocupação desordenada e atividades degradantes como a extração das salinas, que prejudicam o equilíbrio natural dos ambientes, alterando a superfície através da impermeabilização, aterramentos e outras atividades como a contaminação, não levando em conta a importância biológica e natural desses elementos para os ambientes estuarinos, além de que se não controlados serão capazes de comprometer gradativamente a qualidade ambiental do mesmo.

As análises e procedimentos metodológicos utilizados nesta pesquisa, como a caracterização das unidades geoambientais, constituem-se em ferramentas relevantes para a aplicação do desenvolvimento sustentável, o que pode constituir posteriormente estudos indispensáveis ao ordenamento territorial de uma região.

Desta maneira, uma vez que elaborado o diagnóstico das potencialidades e limitações dos recursos naturais da área em questão, é possível identificar os impactos ambientais que ocorrem nas unidades de forma individualizada, possibilitando o estabelecimento de orientações e diretrizes para um melhor uso/ocupação do solo, contribuindo para promover a sustentabilidade da região.

A partir disto, elaborou-se o quadro 2, que traz um diagnóstico ambiental da área em questão, englobando e relacionando as unidades geomorfológicas presentes na área, as limitações, 
potencialidades e traz propostas, com fins ao ordenamento do uso dos recursos, contenção de impactos e recuperação dos ambientes já degradados.

\begin{tabular}{|c|c|c|c|}
\hline \multicolumn{4}{|c|}{$\begin{array}{r}\text { Quadro 2: Limitações, vulnerabilidades, potencialidades e propostas } \\
\text { Pacoti, Ceará }\end{array}$} \\
\hline Unidades geomorfológicas & Limitações & Potencialidades & Propostas \\
\hline $\begin{array}{c}\text { Planície Litorânea: } \\
\text { feições de praia, campos de } \\
\text { dunas móveis, campo de } \\
\text { dunas fixas, paleodunas e } \\
\text { planície flúvio-marinha. }\end{array}$ & $\begin{array}{l}\text { Grandes profundidades do rio } \\
\text { e do mar, limitando a } \\
\text { balneabilidade. } \\
\text { Solo limitante para cultivo em } \\
\text { razão dos altos níveis de } \\
\text { salinidade. } \\
\text { Infraestrutura básica } \\
\text { deficiente. }\end{array}$ & $\begin{array}{c}\text { Favorável para a prática de } \\
\text { esportes aquáticos como: } \\
\text { kitesurf, stand up paddle e } \\
\text { caiaque. } \\
\text { Atividade extrativista de } \\
\text { caranguejo controlada; } \\
\text { Grande potencial para o } \\
\text { turismo ecológico e } \\
\text { navegação. }\end{array}$ & $\begin{array}{c}\text { Infraestrutura básica } \\
\text { adequada; } \\
\text { Retirada de construções } \\
\text { inadequadas em espaços não } \\
\text { permitidos (dunas, mangue e } \\
\text { margens do rio). } \\
\text { Controle da retirada } \\
\text { inadequada de sedimentos dos } \\
\text { mananciais. }\end{array}$ \\
\hline $\begin{array}{l}\text { Planície Flúvio-Lacustre e } \\
\text { áreas de inundação sazonal }\end{array}$ & $\begin{array}{l}\text { Zonas inapropriadas para } \\
\text { construção em razão do } \\
\text { elevado potencial de } \\
\text { alagamento. }\end{array}$ & $\begin{array}{l}\text { Propícia ao cultivo de vegetais } \\
\text { e cereais por ser uma área } \\
\text { plana, com solo rico em } \\
\text { nutrientes, além de potencial } \\
\text { hídrico subterrâneo elevado; } \\
\text { Favorável à prática de turismo } \\
\text { para balneabilidade. }\end{array}$ & $\begin{array}{l}\text { Infraestrutura básica adequada } \\
\text { para evitar contaminação } \\
\text { hídrica superficial e } \\
\text { subterrânea; } \\
\text { Retirada de construções } \\
\text { irregulares que ponha em risco } \\
\text { a integridade ambiental destes } \\
\text { espaços. } \\
\end{array}$ \\
\hline Planície Fluvial do rio Pacoti & $\begin{array}{l}\text { Zonas inapropriadas para } \\
\text { construção em razão do } \\
\text { elevado potencial de } \\
\text { alagamento. }\end{array}$ & $\begin{array}{l}\text { Favorável para atividade } \\
\text { extrativista e de cultivo, da } \\
\text { carnaúba e de vegetais e } \\
\text { cereais por ser uma área com } \\
\text { relevo plano, com cotas de } 5 \text { a } \\
10 \text { metros. Com solo rico em } \\
\text { nutrientes e água em grande } \\
\text { parte do ano. }\end{array}$ & $\begin{array}{c}\text { Controle do destino e } \\
\text { quantidade da madeira } \\
\text { retirada; } \\
\text { Retirada e realocação de } \\
\text { comunidades em situação de } \\
\text { risco as margens dos rios. }\end{array}$ \\
\hline $\begin{array}{l}\text { Glacis de Deposição Pré- } \\
\text { Litorâneos: tabuleiros } \\
\text { costeiros dissecados em } \\
\text { interflúvios tabulares }\end{array}$ & $\begin{array}{l}\text { Solos medianamente erodíveis } \\
\text { e passíveis de lixiviação. }\end{array}$ & $\begin{array}{l}\text { Favorável à ocupação urbana, } \\
\text { cultivo e agropecuária, em } \\
\text { razão dos solos planos e com } \\
\text { média capacidade de oferta } \\
\text { hídrica subterrânea. }\end{array}$ & $\begin{array}{c}\text { Ordenamento da retirada de } \\
\text { fonólito; } \\
\text { Infraestrutura básica } \\
\text { adequada; } \\
\text { Coibição da retirada de } \\
\text { vegetação. }\end{array}$ \\
\hline
\end{tabular}

Quadro 02. Limitações, vulnerabilidades, potencialidades e propostas para as unidades geomorfológicas do estuário do Rio Pacoti, Ceará. Fonte: Barbosa (2016).

\section{CONSIDERAÇÕES FINAIS}

A situação atual dos recursos naturais no estuário do rio Pacoti, vem sendo afetadas por atividades de cunho antrópico, que degradam massivamente as áreas protegidas, em razão da ausência do monitoramento e fiscalização eficientes, que venham a coibir tais danos ambientais. Tal condição não favorece a conservação das paisagens naturais locais, refletindo o estado de degradação do complexo estuarino e da manutenção de um quadro efetivo de ausência de um ordenamento do uso e ocupação do solo no setor do estuário.

Neste sentido, é possível compreender a relevância da Geoecologia da Paisagem, pois proporciona por intermédio de uma análise integrada, a visualização das condições naturais e seu estado de conservação atual, além de fornecer subsídios que possibilitam a todas as instâncias governamentais e a sociedade civil planejarem suas ações e reforçar o quadro de fiscalização, para perpetuação longínqua desses ambientes de elevada geodiversidade. 
Desta forma, é possível concluir que a análise geoecológica demonstrou eficácia na elaboração de propostas de manejo ambiental para o estuário do rio Pacoti, fornecendo-lhes um diagnóstico atualizado, compatibilizando os usos em função das potencialidades e limitações locais, demandando a emergência de um quadro mais harmônico no que se refere à relação sociedade/natureza.

As ações de planejamento elaboradas, refletidas no quadro de propostas, têm caráter de urgência de aplicação, necessitando de monitoramento contínuo, vista a necessidade de manutenção das medidas. Ressalta-se, entretanto, que qualquer ação conservacionista deve conjugar os âmbitos sociais e governamentais, desenvolvendo políticas públicas que atuem em consonância com as ações dos Comitês de Bacias Hidrográficas, órgãos essenciais no planejamento e tomada de decisões, no que diz respeito às unidades de planejamento hidrográficas.

\section{REFERÊNCIAS}

BARRA, O. A. O. L.; SILVA, N.S.; LIMA, D. B. ; Vasconcelos, F. P., 2014. Caracterização Geoambiental e os Conflitos Existentes na Sub-Bacia Hidrográfica do Baixo Pacoti, Ceará - Brasil. Revista da Casa da Geografia de Sobral, Sobral/CE, v. 2, n. 16, p. 66-83, dez. 2014. Disponível em: 〈http://uvanet.br/rcgs>. Acesso em: 22 de jul. 2015.

CEARÁ. Diário Oficial do Estado. Série 2 ano III, n³4, caderno 1/2. Fortaleza: editoração SEAD, 17/02/2000.

FARIAS, J. F. Aplicabilidade da Geoecologia das Paisagens no planejamento ambiental da bacia hidrográfica do rio Palmeira-Ceará/Brasil. 2015. 223 f. Tese (Doutorado em geografia)- Universidade Federal do Ceará, Fortaleza-CE, 2015.

GORAYEB, A.; SILVA, E. V. ; MEIRELES, A. J. A. Impactos Ambientais e Propostas de Manejo Sustentável para a Planície Flúvio-Marinha do Rio Pacoti - Fortaleza/Ceará. Sociedade \& Natureza, Uberlândia, v. 33, n. 17, p. 143-152, ago. 2005.

GORAYEB, A.; SILVA, E. V. ; MEIRELES, A. J. A. Meio Ambiente e Condições de Sustentabilidade da Planície Flúvio-Marinha do Rio Pacoti - Ceará - Brasil. Geoambiente On-line, Jataí/GO, n. 2, p. 1-17, janjun. 2004.

MANN, K.H. Ecology of coastal waters. 2 ed. John Wiley and Sons, Ltd. New York, USA. 2000. 100 p. MEIRELES, A. J. A., 2012. Geomorfologia costeira: funções ambientais e sociais. Fortaleza: Ediçoes UFC, $489 \mathrm{p}$.

MEIRELES, A. J. A.; SILVA, E.V. Abordagem geomorfológica para a realização de estudos integrados para o planejamento e gestão em ambientes flúvio-marinhos. Scripta Nova. Revista electrónica de geografía y ciencias sociales, Universidad de Barcelona, vol. VI, núm. 118, 15 de julho de 2002. [ISSN: 1138-9788].

MINISTÉRIO DO MEIO AMBIENTE. Erosão e progradação no litoral brasileiro. Dieter Muehe, organizador. - Brasília: MMA. 2006. 476 p. 
NASCIMENTO, F. R., 2003. Recursos naturais e desenvolvimento sustentável: subsídios ao manejo geoambiental na Sub-bacia do Baixo Pacoti - Ceará. 2003. Dissertação (Mestrado Acadêmico em Geografia) - Universidade Estadual do Ceará, Centro de Ciências e Tecnologia. 144p.

NASCIMENTO, F. R.; CARVALHO, O. Sub-Compartimentação Topográfica, Caracterização e Descrição das Formas de Relevo na Bacia Metropolitana do Pacoti em Fortaleza, CE. Revista Brasileira de Geomorfologia, v. 1, n. 7, p. 19-26, jan. 2006.

PINTO-COELHO, R. M.; HAVENS, K. Crise nas Águas: Educação, ciência e governança, juntas, evitando conflitos gerados por escassez e perda da qualidade das águas. Belo Horizonte: Recóleo, 2015. $162 \mathrm{p}$.

RODRIGUEZ, J. M. M.; SILVA, E. V. Planejamento e gestão ambiental: subsídios da geoecologia das paisagens e da teoria geossistêmica. Fortaleza: edições UFC, 2013.

SALES, V. C.. Sistemas naturais e degradação sócio-ambiental no estado do Ceará. In: Diagnóstico sócioambiental do Estado do Ceará: O olhar da sociedade civil. Fortaleza: Banco do Nordeste do Brasil, 1993, p.09-36.

SOUZA, M.J.N. 2000. Bases Naturais e esboço do zoneamento geoambiental do estado do Ceará. In: Lima, L. C., MORAIS, J. O. e SOUZA, M. J. N. (Orgs). Compartimentação territorial e gestão regional do Ceará. Fortaleza: FUNECE.

SUGUIO, K. Geologia do Quartenário: mudanças ambientais. São Paulo: Oficina de Textos, 2010. 408 p.

\section{AGRADECIMENTOS}

Somos gratos ao Conselho Nacional de Desenvolvimento Científico e Tecnológico (CNPq) por financiar esta pesquisa, através do Programa Institucional de Bolsas de Iniciação Científica (PIBIC).

Recebido em: 14/08/2016

Aceito para publicação em: 01/10/2016 